ISPRS Archives XXXVIII-8/W3 Workshop Proceedings: Impact of Climate Change on Agriculture

\title{
SAMPLING DESIGN FOR GLOBAL SCALE MAPPING AND MONITORING OF AGRICULTURE
}

\author{
Shashikant A. Sharma and Jai Singh Parihar
}

Space Applications Centre, Indian Space Research Organisation, Ahmedabad, India, sasharma@sac.isro.gov.in

KEYWORDS: Global Agriculture, Sampling, Stratification, Crop Monitoring, MERIS.

\section{ABSTRACT:}

In the changing global environment there is a need for an operational system for monitoring of world food crop production using satellite observations. It is useful in two primary missions - food security in developing countries, and forecasting production available for global market of agricultural crops. In the present study, grids of size (i) $5^{\circ} \mathrm{X} 5^{\circ}$ (ii) $1^{\circ} \mathrm{X} 1^{\circ}$ (iii) $30^{\prime} \mathrm{X} 30^{\prime}$ (iv) $1^{\prime}{ }^{\prime} \mathrm{X} 15^{\prime}$ (v) $7^{\prime} 5^{\prime} \mathrm{X} 7.5^{\prime}$ and (vi) 5’X5' were generated and percent crop area was calculated for each grid of all sizes using MERIS landuse/landcover data of $300 \mathrm{~m}$ resolution. The grid size of 15'X15' was found to be optimum for global monitoring, as there is not much change in the distribution of the grids after reducing the sample size. Using the 'cumulative square-root of frequency method five stratas was defined, which reduces the variance of the population estimate by sampling.

\section{INTRODUCTION}

To address the massive area to be covered, it is essential to develop a sampling strategy for analysis of satellite data. The study was conducted to evolve a effective sampling plan for estimation of global agriculture and monitoring its condition at various scales. The stratification objectives are twofold: (i) reducing the variance of estimate and (ii) allowing a regional tuning of the classification parameters to take into account the regional characteristics.

In 1974, the Large Area Crop Inventory Experiment (LACIE) - a joint effort of NASA, USDA and NOAA attempted forecasting harvests in important wheat producing areas of the world. The sampling unit size was 5 X 6 nautical miles and stratified random sampling approach was used to get about 2.2 percent sampling error and the production estimation to satisfy 90/90 criterion (LACIE, 1978). It was later on followed by the project Agriculture and Resource Inventory Survey through Aerospace Remote Sensing (AgRISTARS). The goal of AgRISTARS was to determine the usefulness, cost and extent to which aerospace remote sensing data can be integrated into existing and future system.

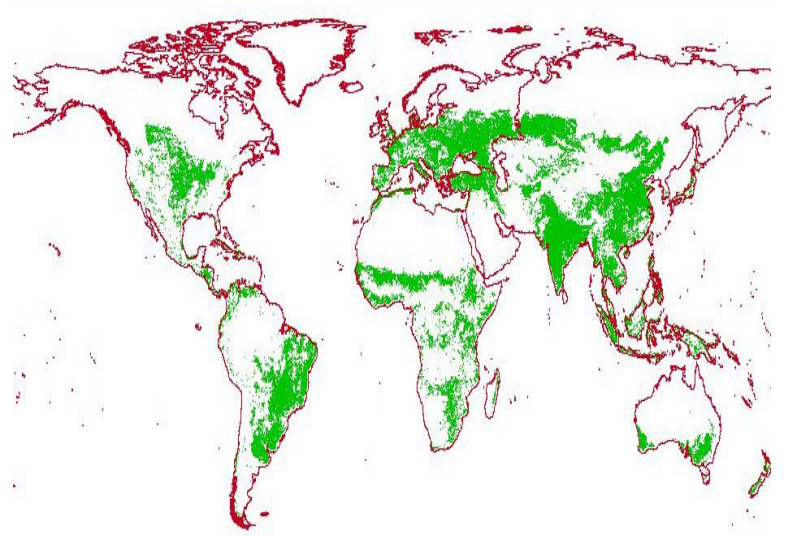

Figure 1: Agriculture Regions Over the Globe

\section{METHODOLOGY}

As shown in figure 1 and figure 2, the distribution of crop varies a lot together with its concentration and vigor. In the present study, grids of size (i) $5^{\circ} \mathrm{X} 5^{\circ}$ (ii) $1^{\circ} \mathrm{X} 1^{\circ}$ (iii) $30^{\prime} \mathrm{X} 30^{\prime}$ (iv) $15^{\prime} \mathrm{X} 15^{\prime}$ (v) $7.5^{\prime} \times 7.5^{\prime}$ and (vi) $5^{\prime} \times 5^{\prime}$ 'were generated with proper codes for the whole world. The grids were generated over the land area excluding the Antarctica region. Percent crop area was calculated for each grid of all sizes using MERIS land use / land cover data. It is $300 \mathrm{~m}$ resolution raster data of the Globecover global land cover map for the period from December 2004 to June 2006. The data is in geographic coordinates in a Plate-Carrée projection (WGS84 ellipsoid) with image size as 129595 X 64800 pixels.. This global Land Cover map is derived by an automatic and regionally-tuned classification of a MERIS FR time series. Its 22 land cover classes are defined with the UN Land Cover Classification System (LCCS) (Bicheron et al., 2008).

\begin{tabular}{|c|c|c|c|}
\hline Grid Size & $\begin{array}{l}\text { Number of } \\
\text { Grids }\end{array}$ & $\begin{array}{l}\text { Agriculture } \\
\text { Grids }\end{array}$ & $\begin{array}{l}\text { Per } \\
\text { cent }\end{array}$ \\
\hline $5^{\circ} \times 5^{\circ}$ & 1116 & 597 & 53.5 \\
\hline $1^{\circ} \times 1^{\circ}$ & 18714 & 9846 & 52.6 \\
\hline $30^{\prime} \times$ X 30' & 69012 & 31526 & 45.7 \\
\hline $15^{\prime} \times 15^{\prime}$ & 263002 & 115545 & 43.9 \\
\hline $7.5^{\prime} \times 7.5^{\prime}$ & 1022523 & 426902 & 41.8 \\
\hline $5^{\prime} \times 5^{\prime}$ & 2276188 & 915582 & 40.2 \\
\hline
\end{tabular}

Table 1: Global Grid statistics for crop monitoring

Total number of grids and the grids having agriculture, obtained using various grid sizes are shown in the table-1. Number of grids having agriculture in different ranges over various continents are shown in table-3. 


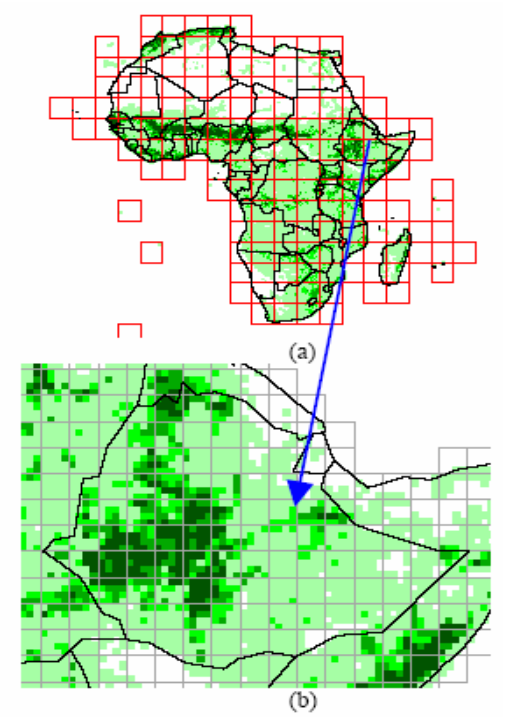

Figure 2. Grids of size 15’X15' for (a) Africa Continent and (b) Ethiopia Country Shown in Five Equal Ranges of Percent Crop Cover

\section{RESULTS AND DISCUSSION}

There is wide range of variability in agriculture area over the whole world..Table-2 shows the distribution of grids with respect to percent agriculture in each grid. More than 50 percent of grids are non-agriculture grids. Distribution of the grids in intervals of 5 percents shows a skew distribution of the agriculture grids.

\begin{tabular}{|c|c|c|c|c|}
\hline \multirow[b]{2}{*}{ Range of crop(\%) } & 30'X30 & 15'X15 & 7.5'X7.5 & 5 'X5 \\
\hline & \multicolumn{4}{|c|}{ Percent of grids in each range } \\
\hline 0 & 54.32 & 61.41 & 64.4 & 59.8 \\
\hline $0-5$ & 10.38 & 8.17 & 7.0 & 7.5 \\
\hline $5-10$ & 4.60 & 3.63 & 3.2 & 3.5 \\
\hline $10-15$ & 3.40 & 2.76 & 2.4 & 2.6 \\
\hline $15-20$ & 2.96 & 2.28 & 2.0 & 2.2 \\
\hline $20-25$ & 2.53 & 2.04 & 1.8 & 1.9 \\
\hline $25-30$ & 2.30 & 1.84 & 1.6 & 1.7 \\
\hline $30-35$ & 2.05 & 1.59 & 1.4 & 1.6 \\
\hline $35-40$ & 1.79 & 1.51 & 1.3 & 1.5 \\
\hline $40-45$ & 1.64 & 1.41 & 1.3 & 1.4 \\
\hline $45-50$ & 1.57 & 1.32 & 1.2 & 1.3 \\
\hline $50-55$ & 1.38 & 1.23 & 1.1 & 1.3 \\
\hline $55-60$ & 1.33 & 1.15 & 1.1 & 1.2 \\
\hline $60-65$ & 1.21 & 1.13 & 1.0 & 1.2 \\
\hline $65-70$ & 1.25 & 1.07 & 1.0 & 1.2 \\
\hline $70-75$ & 1.23 & 1.08 & 1.0 & 1.2 \\
\hline $75-80$ & 1.23 & 1.08 & 1.1 & 1.2 \\
\hline $80-85$ & 1.21 & 1.12 & 1.1 & 1.3 \\
\hline $85-90$ & 1.15 & 1.18 & 1.2 & 1.4 \\
\hline $90-95$ & 1.25 & 1.35 & 1.4 & 1.7 \\
\hline $95-100$ & 1.23 & 1.66 & 2.3 & 3.3 \\
\hline
\end{tabular}

Table 2 : Comparative Statistics of Crop Proportion in Different Sizes of Grids
Table 2 and 3 shows that the grid size of $15^{\prime} \mathrm{X} 15^{\prime}$ ' was found to be optimum for global monitoring. There is not much change in the distribution of the grids after reducing the size from 15 'X15'. The distribution of grids in different continents is seen in table-3. Due to large variability in the crop proportion in grids, simple random sampling gives high variance in the estimation. The average of all grids is 35.8 with a standard deviation and coeff. of variation (CV) as 31.3 and $87.5 \%$ respectively. Stratified random sampling approach was used for dividing the population into different stratas. Based on clustering algorithm, the total number of $15^{\prime} \mathrm{X} 15^{\prime}$ girds was divided in to six stratas including non- agriculture grids. The stratas were defined based on percent agriculture in each grid as shown in table-4. They were (i) A : 70-100 \% (ii) B : 40-70\% (iii) C : 20-40 \% (iv) D : 5-20 \% (v) E : 0-5 \%(vi) X : 0 \% (Nonagriculture). The global data in $15^{\prime} \times 15^{\prime}$ grids stratified into six stratas is shown in figure 3.

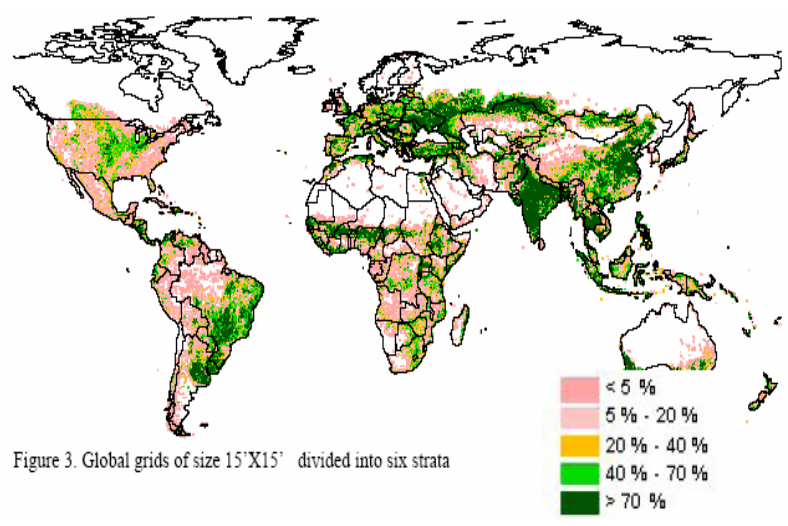

Using the 'cumulative square-root of frequency' method developed by Dalenius \& Hodges(1959) the stratas were defined as shown in table-5. They are (i) A : 75-100 \% (ii) B : 50-75 \% (iii) C : 30-50 \% (iv) $\mathrm{D}: 10-30 \%$ (v) $\mathrm{E}: 0-10 \%(v i) \mathrm{X}: 0 \%$ (Non-agriculture). There is a reduction in CVs of all stratas except $\mathrm{E}$ type.

As shown in figure-4, weekly NDVI composites from MODIS data over the crop growth period was generated for monitoring crop condition at all grid levels. Any anomaly in NDVI may be scrutinized further at lower grid level and crop condition can be assessed. This will help in drought monitoring and crop condition assessment on the global scale.

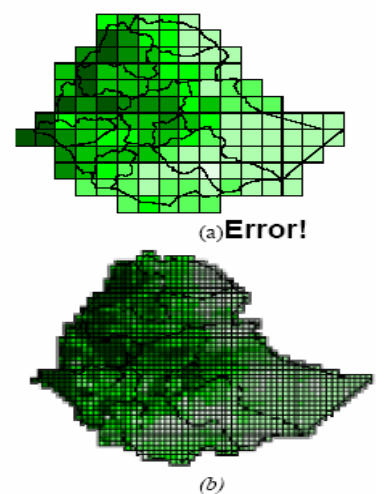

Figure 4. (a) $1^{\circ} \mathrm{X} 1^{\circ}$ and (b) $15^{\prime} \mathrm{X} 15^{\prime}$ ' Grids of Ethiopia Showing NDVI for the Week July 27-Aug 4, 2008 
ISPRS Archives XXXVIII-8/W3 Workshop Proceedings: Impact of Climate Change on Agriculture

\section{CONCLUSION}

The study shows an effective sampling plan for estimation of global agriculture and monitoring its condition at various scales. The grid size of $15^{\prime} \mathrm{X} 15^{\prime}$ ' was found to be optimum for global monitoring. There is not much change in the distribution of the grids after reducing the size from $15^{\prime} \mathrm{X} 15$ '. Using the 'cumulative

\begin{tabular}{|c|c|c|c|c|c|c|}
\hline $5^{\circ} \times 5^{\circ}$ & 0 & $0-20$ & $20-40$ & $40-60$ & $60-80$ & $80-100$ \\
\hline Asia & 39.3 & 37.8 & 9.9 & 7.1 & 4.0 & 1.9 \\
\hline Africa & 24.8 & 56.1 & 14.0 & 5.1 & 0.0 & 0.0 \\
\hline Australia & 45.8 & 43.8 & 4.2 & 6.3 & 0.0 & 0.0 \\
\hline N America & 67.8 & 26.0 & 5.4 & 0.8 & 0.0 & 0.0 \\
\hline S America & 16.2 & 58.1 & 14.3 & 6.7 & 4.8 & 0.0 \\
\hline Europe & 53.8 & 18.5 & 11.8 & 7.6 & 8.4 & 0.0 \\
\hline Oceania & 70.8 & 29.2 & 0.0 & 0.0 & 0.0 & 0.0 \\
\hline World & 46.5 & 36.9 & 8.9 & 4.7 & 2.5 & 0.5 \\
\hline $1^{\circ} \times 1^{\circ}$ & 0.0 & $0-20$ & $20-40$ & $40-60$ & $60-80$ & $80-100$ \\
\hline Asia & 16.7 & 39.4 & 14.0 & 10.5 & 9.2 & 10.1 \\
\hline Africa & 17.7 & 51.4 & 15.5 & 8.8 & 4.1 & 2.6 \\
\hline Australia & 35.9 & 40.4 & 7.4 & 6.5 & 5.4 & 4.5 \\
\hline N America & 13.6 & 60.9 & 15.9 & 7.3 & 2.2 & 0.1 \\
\hline S America & 7.6 & 57.6 & 12.2 & 9.8 & 8.2 & 4.7 \\
\hline Europe & 9.2 & 29.9 & 21.4 & 18.1 & 12.9 & 8.5 \\
\hline Oceania & 10.4 & 75.4 & 9.0 & 4.3 & 0.9 & 0.0 \\
\hline World & 53.1 & 23.8 & 8.9 & 6.2 & 4.4 & 3.5 \\
\hline $30^{\prime}$ X 30' & 0 & $0-20$ & $20-40$ & $40-60$ & $60-80$ & $80-100$ \\
\hline Asia & 53.0 & 17.7 & 8.5 & 6.3 & 6.1 & 8.5 \\
\hline Africa & 43.4 & 31.7 & 11.4 & 6.4 & 3.9 & 3.2 \\
\hline Australia & 74.2 & 13.2 & 3.2 & 2.6 & 3.2 & 3.7 \\
\hline N America & 73.8 & 16.4 & 5.9 & 2.8 & 0.9 & 0.2 \\
\hline S America & 26.2 & 39.1 & 11.5 & 8.4 & 9.1 & 5.7 \\
\hline Europe & 46.4 & 14.8 & 11.9 & 10.8 & 9.5 & 6.6 \\
\hline Oceania & 42.4 & 41.8 & 8.3 & 4.5 & 2.2 & 0.8 \\
\hline World & 54.3 & 21.3 & 8.7 & 5.9 & 4.9 & 4.8 \\
\hline 15'X15' & 0 & $0-20$ & $20-40$ & $40-60$ & $60-80$ & $80-100$ \\
\hline Asia & 55.2 & 15.2 & 7.5 & 6.0 & 6.0 & 10.1 \\
\hline Africa & 47.3 & 28.2 & 10.0 & 6.2 & 4.1 & 4.1 \\
\hline Australia & 76.6 & 10.4 & 3.0 & 2.3 & 3.0 & 4.6 \\
\hline N America & 74.5 & 15.1 & 5.8 & 3.1 & 1.1 & 0.3 \\
\hline S America & 29.8 & 35.7 & 10.1 & 8.4 & 8.7 & 7.3 \\
\hline Europe & 45.9 & 13.9 & 11.5 & 10.4 & 9.7 & 8.7 \\
\hline Oceania & 28.2 & 43.3 & 12.3 & 8.0 & 5.3 & 2.9 \\
\hline World & 61.4 & 16.8 & 7.0 & 5.1 & 4.4 & 5.3 \\
\hline $7.5^{\prime} X 7.5^{\prime}$ & 0 & $0-20$ & $20-40$ & $40-60$ & $60-80$ & $80-100$ \\
\hline Asia & 57.5 & 13.3 & 6.5 & 5.5 & 5.6 & 11.6 \\
\hline Africa & 51.8 & 24.4 & 8.7 & 5.9 & 4.2 & 5.0 \\
\hline Australia & 78.7 & 8.5 & 2.6 & 2.1 & 2.7 & 5.4 \\
\hline N America & 75.6 & 13.9 & 5.6 & 3.2 & 1.3 & 0.5 \\
\hline S America & 34.4 & 31.2 & 9.5 & 8.1 & 8.3 & 8.5 \\
\hline Europe & 45.8 & 13.9 & 10.6 & 9.6 & 9.7 & 10.5 \\
\hline Oceania & 20.3 & 38.9 & 15.0 & 10.7 & 8.6 & 6.5 \\
\hline World & 64.4 & 14.6 & 6.1 & 4.7 & 4.1 & 6.1 \\
\hline 5'X5' & 0 & $0-20$ & $20-40$ & $40-60$ & $60-80$ & $80-100$ \\
\hline Asia & 58.9 & 12.2 & 6.0 & 5.1 & 5.4 & 12.3 \\
\hline Africa & 54.1 & 22.5 & 8.0 & 5.6 & 4.2 & 5.6 \\
\hline Australia & 79.8 & 7.5 & 2.5 & 1.9 & 2.4 & 5.8 \\
\hline N America & 76.3 & 13.1 & 5.3 & 3.2 & 1.4 & 0.7 \\
\hline S America & 37.2 & 28.8 & 9.0 & 7.7 & 8.1 & 9.3 \\
\hline Europe & 46.0 & 13.9 & 10.0 & 9.0 & 9.4 & 11.7 \\
\hline Oceania & 16.6 & 36.6 & 14.9 & 11.3 & 10.5 & 10.1 \\
\hline World & 59.8 & 15.8 & 6.7 & 5.2 & 4.8 & 7.7 \\
\hline
\end{tabular}

Table 3: Grid Statistics Showing Distribution of Cropped Region for Continents and the World square-root of frequency method five stratas was defined. This reduces the variance of the population estimate by sampling. Weekly NDVI composites from MODIS data can be effectively used for monitoring crop condition at all grid levels. This will help in drought monitoring and crop condition assessment on the global scale. 
ISPRS Archives XXXVIII-8/W3 Workshop Proceedings: Impact of Climate Change on Agriculture

\begin{tabular}{|c|c|r|r|r|r|r|}
\hline 15'X15' Stratas & Range (\%) & \multicolumn{1}{|c|}{ No. of grids } & \multicolumn{1}{c|}{ Percent of grid } & \multicolumn{1}{c|}{ Avg } & \multicolumn{1}{c|}{ Std. Dev } & Coff. of Var. \\
\hline X & 0 & 183879 & 61.4 & 0 & 0 & \\
\hline E & $0-5$ & 24465 & 8.2 & 2.4 & 1.4 & 58.6 \\
\hline D & $5-20$ & 25949 & 8.7 & 12.1 & 4.3 & 35.9 \\
\hline C & $20-40$ & 20908 & 7.0 & 29.8 & 5.8 & 19.3 \\
\hline B & $40-70$ & 21860 & 7.3 & 54.7 & 8.7 & 15.9 \\
\hline A & $70-100$ & 22363 & 7.5 & 86.8 & 8.9 & 10.2 \\
\hline
\end{tabular}

Table 4: Stratification of 15’ X 15’ Grids for Global Crop Monitoring Using Clustering

\begin{tabular}{|c|c|r|r|r|r|r|}
\hline 15'X15' Stratas & Range (\%) & No. of grids & Percent of grid & \multicolumn{1}{c|}{ Avg } & \multicolumn{1}{l|}{ Std. Dev } & Coff. of Var. \\
\hline X & 0 & 183879 & 61.4 & 0 & 0 & \\
\hline E & $0-10$ & 35344 & 11.8 & 4.1 & 2.9 & 70.73 \\
\hline D & $10-30$ & 26685 & 8.9 & 19.6 & 5.8 & 29.59 \\
\hline C & $30-50$ & 17466 & 5.8 & 40.1 & 5.8 & 14.46 \\
\hline B & $50-75$ & 16926 & 5.7 & 62.7 & 7.3 & 11.64 \\
\hline A & $75-100$ & 19124 & 6.4 & 89.1 & 7.3 & 8.19 \\
\hline
\end{tabular}

Table 5: Stratification of 15’ X 15’ Grids for Global Crop Monitoring Using Square-Root Method

\section{REFERENCES}

Bicheron P.,Defourny P, Brockmann C, Schouten L, Vancutsem C, Huc M, Bontemps S, Leroy M., Achard F, Herold M, Ranera F, Arino O. GLOBCOVER: Products Description and Validation Report. 2008.
Dalenius \& Hodges JL (Jr) (1959), Minimum variance stratification, Journal of the American Statistical Association, Vol-54, pp:88-101.

LACIE Symposium: Proceedings of Technical Sessions (Volume -I) (1978), NASA

ESA Globcover Project led by MEDIAS France/POSTEL 